\title{
ASPECTS OF POPULATION STRUCTURE OF Nacella concinna (Strebel, 1908) (GASTROPODA - NACELLIDAE) AT ADMIRALTY BAY, KING GEORGE ISLAND, ANTARCTICA
}

http://dx.doi.org/10.4322/apa.2014.044

\author{
Maria Isabel Sarvat de Figueiredo ${ }^{1, *}$, Helena Passeri Lavrado ${ }^{1}$ \\ 'Laboratório de Benthos, Departamento de Biologia Marinha, Instituto de Biologia, \\ Universidade Federal do Rio de Janeiro -UFRJ, Ilha do Fundão, RJ, Brazil \\ *e-mail: belfig@gmail.com
}

\begin{abstract}
Antarctic intertidal zones are extremely stressful environments, and the Antarctic limpet Nacella concinna is one of the most conspicuous components of the megafauna, colonizing these areas at Admiralty Bay. This species has the potential to be a biomonitor, since it suffers the direct effects of environmental variations and anthropic impacts. In the summer 2010, specimens of N. concinna were collected at 6 sites in Admiralty Bay, in order to investigate population variability. Most individuals were larger than $20 \mathrm{~mm}$, with positive allometric growth. Females were smaller and usually outnumbered males in the population. The preliminary results showed that limpets near the Brazilian station did not present any atypical values, so it seems that human activities do not significantly affect the population structure. Differences found should be considered a response to natural physical or biological factors.
\end{abstract}

Keywords: Nacella concinna, population structure, Admiralty Bay

\section{Introduction}

Antarctic intertidal zone is extremely stressful, since it is often subject to large environmental variation, such as freezing and ice foot in winter, and melt water runoff in summer (Weihe \& Abele, 2008). The gastropod Nacella concinna (Strebel, 1908) (Figure 1), is the most conspicuous invertebrate of the intertidal megafauna (Kim, 2001), colonizing throughout most of the intertidal zone of Admiralty Bay. This species is physiologically sensitive to freshwater, high temperatures and long aerial exposures (Weihe \& Abele, 2008), suffering the direct effects of environmental variations or anthropic impacts. In addition, as one of the largest herbivorous (Kim, 2001), and the main prey of kelp gull Larus dominicanus Lichtenstein, 1823
(Favero et al., 1997), this gastropod represents an important link between marine and terrestrial ecosystems.

Although several studies of Admiralty Bay benthos (Sicinski et al., 2010), have been carried out in the past 30 years, the knowledge about benthic ecology is still incipient, especially concerning the mollusk Nacella concinna. Recent studies have been focused on physiological and biochemical processes, as well as on the phylogeny of the species (Nakano \& Ozawa, 2007). However, the knowledge about population dynamics is fundamental to understand the ecosystem processes (Jones et al., 2007) and to evaluate the meaning of environmental changes, increasingly evident in the Southern Ocean. 

indicate statistically different means, from post hoc test in ANOVA results.

\begin{tabular}{|c|c|c|c|c|c|c|c|c|}
\hline Sites & n (total) & $\begin{array}{l}\text { Mean } \\
(\mathrm{mm})\end{array}$ & SE & Min & Max & $\begin{array}{c}\text { Sex ratio } \\
(\mathrm{F} / \mathrm{M})\end{array}$ & $\begin{array}{c}\text { Chi- } \\
\text { Square }\end{array}$ & $\mathbf{p}$ \\
\hline 1 & 71 & $36.66^{a}$ & 0.40 & 30.24 & 46.41 & 1.74 & 3.769 & 0.052 \\
\hline 2 & 74 & $30.01^{b}$ & 0.47 & 17.93 & 40.82 & 1.57 & 3.556 & 0.059 \\
\hline 3 & 103 & $26.30^{\circ}$ & 0.36 & 14.33 & 33.55 & 0.96 & 0.044 & 0.833 \\
\hline 4 & 95 & $32.31^{d}$ & 0.59 & 19.54 & 45.03 & 1.74 & 6.720 & $0.009 *$ \\
\hline 5 & 102 & $34.37^{e}$ & 0.38 & 24.20 & 43.74 & 1.83 & 8.824 & $0.003^{*}$ \\
\hline Total & 445 & - & - & - & - & 1.51 & 16.844 & $<0.0001^{*}$ \\
\hline
\end{tabular}

Obs: *Denotes significance $p<0.05$.

$\left(\mathrm{W}=2 \cdot 10^{-5} \mathrm{SL}^{3,6268} ; \mathrm{R}^{2}=0.96\right)$. Females usually outnumbered males in the population, the sex ratio being, $1: 1.51$ (male:female), which is significantly different from 1:1 $\left(\chi^{2}=16.844 ; \mathrm{p}<0.0001\right)$ (Table 1). Furthermore, mean shell size of male limpets ( $35.38 \mathrm{~mm} \pm 4.28 \mathrm{SE}$ ) was significantly higher than those of females $(33.82 \mathrm{~mm} \pm 3.42 \mathrm{SE})$ at site 5 $(t=-2.008 ; \mathrm{p}<0.047)$. Site 2 , where the Brazilian station is located, did not show either abnormal or discrepant values for all the parameters analyzed, being within the range found for all the sites analyzed.

\section{Discussion}

Environmental stress may be the most feasible explanation for the scarceness of limpets with shell size smaller than $20 \mathrm{~mm}$ in the population. Small specimens have high surface-to-volume ratios, being unable to tolerate desiccation conditions, thermal stress and osmotic stress (Kim, 2001; Weihe \& Abele, 2008). So, at the intertidal limit, small limpets are at a disadvantage if compared to the large ones, probably being restricted to lower intertidal levels, or to the sublittoral zone. Kim (2001) also found more females than males in the population of Maxwell Bay, adjacent to Admiralty Bay. This author suggests that, in the case of $N$. concinna, the dominance of females in the intertidal population may be explained by the migratory behaviour. The bias toward females of the species for intertidal $N$. concinna may be a local adaptation to heterogeneous habitats for optimizing reproductive success. Also, in the Maxwell Bay population, similar to Admiralty Bay, females were smaller than males. According to Kim (2001), since the large females appear to put more effort into reproduction than males under food-limited conditions, the former may result in a higher mortality of the females and may lead to a decrease in the proportion of large females in N. concinna population. Finally, positive allometric growth found in the population of this study can be a result of the probable high gonad weight, since summer is a reproductive period of this species (Stanwell-Smith \& Clarke, 1998).

\section{Conclusion}

Our results suggest that the presence of the Brazilian Station does not interfere in the N. concinna population. The differences found between sites seem to be related to natural dynamics of the species as well as a response to physical stress and natural variations in the intertidal zone.

\section{Acknowledgements}

This work was supported by the Brazilian Antarctic Program (PROANTAR), and INCT-APA (CNPq process $\mathrm{n}^{\circ} 574018 / 2008-5$ and FAPERJ process $n^{\circ} \mathrm{E}-16 / 170.023 / 2008$ ) and SECIRM. Maria Isabel Figueiredo thanks to CNPq for the master fellowship under the process $n^{\circ} 132125 / 2010-2$. 


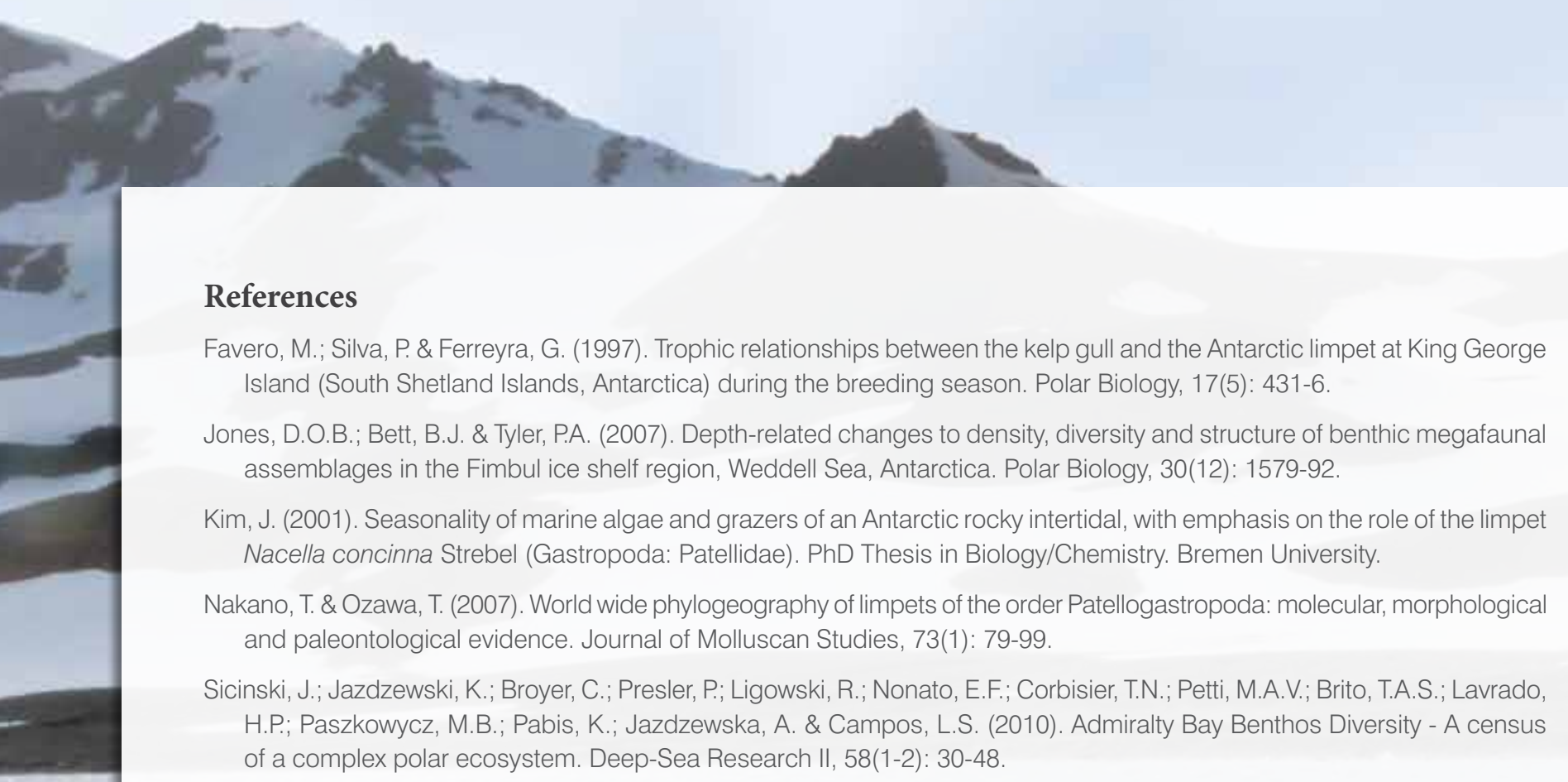

Stanwell-Smith, D. \& Clarke, A. (1998). The timing of reproduction in the Antarctic limpet Nacella concinna (Strebel, 1908) (Patellidae) at Signy Island, in relation to environmental variables. Journal of Molluscan Studies, 64 (1):123-7.

Weihe, E. \& Abele, D. (2008). Differences in the physiological response of inter- and subtidal Antarctic limpets Nacella concinna to aerial exposure. Aquatic Biology, 4: 155-66. 